\title{
TV/Series
}

$10 \mid 2016$

Guerres en séries (II)

\section{Treme - New Orleans : quand la ville s'invente en musique}

Une publication radiophonique

Musique pour l'Imaginaire

\section{OpenEdition}

\section{Journals}

Édition électronique

URL : http://journals.openedition.org/tvseries/1952

DOI : 10.4000/tvseries.1952

ISSN : 2266-0909

\section{Éditeur}

GRIC - Groupe de recherche Identités et Cultures

\section{Référence électronique}

Musique pour l'Imaginaire, "Treme - New Orleans : quand la ville s'invente en musique », TV/Series [En ligne], 10 | 2016, mis en ligne le 01 décembre 2016, consulté le 21 avril 2019. URL : http:// journals.openedition.org/tvseries/1952 ; DOI : 10.4000/tvseries.1952

Ce document a été généré automatiquement le 21 avril 2019

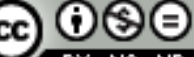

TV/Series est mis à disposition selon les termes de la licence Creative Commons Attribution - Pas d'Utilisation Commerciale - Pas de Modification 4.0 International. 


\title{
Treme - New Orleans : quand la ville s'invente en musique
}

\author{
Une publication radiophonique
}

Musique pour l'Imaginaire

1 Le 27 juin 2016 se tenait à la Dynamo de Banlieues Bleues (Pantin) une journée d'étude consacrée à la série télévisée américaine Treme, créée par David Simon et Eric Overmeyer. Diffusée aux États-Unis entre 2010 et 2013, Treme se situe à la Nouvelle-Orléans après le passage de l'ouragan Katrina qui ravagea, en 2005, une large partie de la ville. Cette fiction novatrice constitue un matériau de premier ordre pour appréhender la ville contemporaine et ses enjeux sociaux et politiques, en interrogeant les liens, complicités et tensions entre espace urbain, patrimoine culturel et luttes sociales. Au cœur de la rencontre se situait la musique, qui représente, à la Nouvelle-Orléans, une richesse commune héritée et présente, un référentiel culturel et identitaire de la société urbaine neo-orléanaise.

2 Cette publication radiophonique vous invite à revivre cette intense rencontre, qui a rassemblé plus d'une dizaine d'intervenant(e)s français(es) et américain(e)s - chercheur (e)s, enseignantes, artistes, musiciens, photographe - en proposant des morceaux choisis de l'ensemble des interventions et débats de la journée.

3 Par ailleurs, vous y écouterez des musiques issues de la série Treme et de la NouvelleOrléans.

Ce média ne peut être affiché ici. Veuillez vous reporter à l'édition en ligne http:// journals.openedition.org/tvseries/1952

5 Équipe organisatrice: Marie-Hélène Bacqué, Sophie Didier, Frédéric Dufaux, Amélie Flamand, Anaïs Marshall, Anne-Marie Paquet-Deyris \& Arnaud Simetière

Partenaires (organisation) : La Dynamo de Banlieues Bleues, Bab Musique

7 Partenaires (soutiens financiers) : MSH Paris-Nord, Université Paris 13, Université Paris Ouest Nanterre La Défense, UMR LAVUE, laboratoires CICLAHO, SERCIA, PLEIADE et CREA 
INDEX

Keywords : music, Treme, Simon David, New Orleans, Katrina (hurricane)

Mots-clés : musique, Treme, Simon David, Nouvelle-Orléans, Katrina (ouragan) 